This is the final version submitted to Studies in Continuing Education and published in 2015. Please do not cite this version. To view the published article use the following: DOI: 10.1080/0158037X.2015.1022717

\title{
Dilemmas in continuing professional learning: Learning inscribed in frameworks or elicited from practice
}

Ann Reich, Donna Rooney and David Boud, University of Technology Sydney, Australia

\section{Abstract}

This paper explores a dilemma in continuing professional learning: the way learning is typically inscribed in continuing professional education (CPE) frameworks differs from that elicited from practice. It examines these differences in relation to both different underlying assumptions about learning and varying epistemological perspectives and, as well as the different purposes of CPE frameworks of professional bodies and organisations. It suggests that the dominant adoption of narrower conceptions of learning in professional organisations' frameworks ignores understandings about work and learning emerging from recent research in the field of workplace learning and focuses on a view that may privilege formal provision. The paper concludes with suggestions for future research directions in developing alternative continuing professional learning frameworks.

\section{Keywords}

Continuing Professional Education; professional learning; practice perspectives; workplace learning.

\section{Introduction}

Continuing education for professional groups has become a prominent concern globally as part of the increased pressure for regulatory frameworks managing professional risk (Fenwick and Nerland 2012). These Continuing Professional Education (CPE) frameworks are not only the domain of statutory registration boards and professional bodies, but are also exercised by organisations who employ professionals (employing organisations). Such frameworks typically identify needed standards, competencies, capabilities and other expectations to become and to continue to be an accepted member of a professional body or employing organisation at a given level. Alongside such requirements are often arrayed a vast provision in the form of courses, workshops, seminars, manuals, online activities, learning logs and so forth to assist professionals to meet them. These activities overwhelmingly assume 
This is the final version submitted to Studies in Continuing Education and published in 2015. Please do not cite this version. To view the published article use the following: DOI: 10.1080/0158037X.2015.1022717

an individualised and acquisition-focused concept of professional learning (Hager 2011).

Such assumptions about learning have been questioned over the past two decades by workplace learning researchers focused on how learning is elicited in and from practice (Eraut, 2012; Malloch, Cairns, Evan and O'Connor 2011; Hager 2011; Hager, Lee, and Reich 2012a). Yet, despite these shifts in contemporary understandings of learning at work, many professional bodies have moved little from their established position. This is evidenced by the ubiquity of courses, workshops and other formally structured activities of many professional bodies. Similarly frameworks of standards and competencies are typically normative, and methods of assessing learning are often focused on counting participation in events or activities. Even innovations in assessment such as learning logs, professional growth plans (Fenwick 2009), still retain an individualised and acquisitioned-focussed assumption of professional learning.

This paper focuses on this key dilemma within CPE: that is, the understandings of learning often inscribed in CPE frameworks are not reflective of contemporary understandings of professional practice and learning. In this quest we add our voices to those who question the relationship between CPE frameworks and the everyday practices of professional learning (see, for example, Fenwick 2009; Boud and Hager 2012).

This dilemma in the ways learning are inscribed in CPE frameworks and elicited from practice are understood in three ways in this paper. Firstly, the assumptions about learning underlying CPE frameworks are discussed and contrasted with contemporary research on work and learning, particularly the more recent research taking up practice theory perspectives. Secondly, as a further exploration of these differences we suggest that they can be partly explained by differing epistemological assumptions - tentatively suggested here as being primarily nomothetic or ideographic. Thirdly, we contend that the purposes of the frameworks, largely as regulatory mechanisms which 'police' the boundaries of professions, reinforce particular conceptualisations of learning, and privilege certain types of CPE activities. The paper uses examples from our empirical work examining professionals learning through their normal work, to highlight differences in conceptualisations elicited 
This is the final version submitted to Studies in Continuing Education and published in 2015. Please do not cite this version. To view the published article use the following: DOI: 10.1080/0158037X.2015.1022717

through practice from those embedded in framework documents of professional bodies and employing organisations. We conclude by outlining some tensions within these views. We suggest that a more fundamental grounding in the everyday practice of professionals and the conduct of the work in which they are engaged is likely to have a more powerful influence on their learning than decontextualised prescriptions or activities that may be experienced as acts of compliance. The paper concludes with some suggestions for future research agendas in developing alternative continuing professional learning frameworks and the ways in which these frameworks could be more reflective of contemporary understandings of professional learning and practice.

\section{Assumptions about learning}

One way of understanding the tension between professional associations' frameworks and practice-focused studies of professional learning and practice is in relation to differing assumptions about learning embedded in CPE frameworks and in workplace learning research. While certainly not a unified field (see Hager 2011) workplace learning research is increasingly taking an interest in the particularities of learning in workplaces. What workplace learning research has identified is that learning is intrinsically intertwined with work itself, 'no longer treated mainly as a separate activity, but as an ongoing dimension of normal work' (Eraut 2012, p.22). Work acts as the prompt for new learning, its validation and its enactment. Learning opportunities are created through the exigencies of work. Work demands new actions, new activities and new expertise. This means the most powerful determinant of learning is the nature of the work involved and how it is organised. Similarly, interacting with multiple others with different capabilities and different perspectives drives learning. In other words, learning occurs as we practice. Restrictive practice is likely to lead to restrictive learning, expanded practice to expanded learning (Unwin and Fuller 2003).

Recent research within workplace learning has taken up the 'practice turn' (Schatzki, Knorr Cetina and von Savigny 2001). Although inclusive of a number of theoretical perspectives (such as actor-network theory; sociohistorical activity theory; complexity theory, governmentality and ecology) it shares a focus on practices as the unit of analysis rather than the individual, which is common in much of the learning theory underpinning CPE frameworks. It uses the resources of practice perspectives to reconceptualise 
This is the final version submitted to Studies in Continuing Education and published in 2015. Please do not cite this version. To view the published article use the following: DOI: 10.1080/0158037X.2015.1022717

current thinking about learning, in particular socio-cultural conceptions of learning. Six prominent threads in theorising professional practice and learning are that practice is: collective and a situated process - a knowing-inpractice (Gherardi 2012) which links working, knowing, organising, learning and innovating; a socio-material phenomenon (Fenwick and Nerland 2014; Fenwick, Edwards, and Sawchuck 2011; Gherardi 2000); embodied; relational; exists and evolves in historical and social contexts; and is emergent (Reich and Hager 2014). This perspective "challenges prominent paradigms in learning theory by conceptualising learning as practice and as occurring via and in practice" (Schatzki 2012 vi). Professional practice and the learning entwined is thus highly contextualised, responding to the 'messiness', unpredictability and complexity of everyday working.

This is in contrast to the underlying assumptions of CPE frameworks based on an acquisition and transfer metaphor of learning - knowledge is acquired and possessed by a person, from whom it can be transferred. Learning is treated as a product or thing, separated from its context (Hager and Hodkinson 2009). The implications of the use of this common metaphor in CPE is that learning is almost solely focused on individuals and their learning. Further, there is an over-simplification of the nature of professional practice and a privileging of the use of 'experts' who 'know' what is required. Content is delivered in formal activities, with a subsequent devaluing of learning in practice. There is a "pre-specification and standardisation of the content of what is learnt" (see Boud and Hager (2012) for a more detailed account). These assumptions underlying CPE are supported by Fenwick's research in Canada (2009). The assumptions of learning underpinning these programmes and assessment are that there is an individualised acquisition of knowledge and skills; that learning is acquired through participation in specially designed activities and that the professional body can "predetermine and regulate the knowledge most worthwhile for a professional to learn regardless of constantly shifting contexts of practice" (Fenwick 2009: 230).

The assumptions underpinning CPE frameworks can thus be seen as largely ignoring the collective nature of practice and learning in workplaces (Hager and Johnsson 2012). It assumes that professional practice and the learning for this practice is specifiable and usually quantifiable, while practice perspectives foreground the chaotic, complex and changing nature of practice, which is emergent and relational - between human and non-human 
This is the final version submitted to Studies in Continuing Education and published in 2015. Please do not cite this version. To view the published article use the following: DOI: 10.1080/0158037X.2015.1022717

actors. Learning is "irreducible to the sum of its parts, whilst drawing on specifiable and non-specifiable aspects only obtained through engagement in practice" (Hager and Johnsson 2012: 249). Therefore this collective learning practice emerges in complex and unanticipated ways which can not be normatively prescribed, despite the efforts of many CPE and CPL frameworks.

\section{Understanding the dilemma - nomothetic or ideographic}

Another way to understand the dilemma is to see it as a difference in epistemology: between a nomothetic and an ideographic view. A nomothetic perspective is one half of a binary, derived from generalisations of expert informants. The term nomothetic was originally introduced by philosopher Wilhelm Windelband in the 1880s. It has sparked epistemological debates, and in particular within education, history and psychology (Mos 1998). While not taking up these debates, we see the binary as providing a helpful contrast for our task at hand. Underpinning assumptions of the nomothetic are that the world can be known through generalisations derived from systematic investigation. Nomos, in ancient Greek, refers to "The body of law, especially that governing human behaviour" (online dictionary).

The CPE processes of professional bodies could be described as nomothetic. These processes typically take the form of statements of competences or capabilities or perhaps simply knowledge and skills. Competencies, standards or capability frameworks are usually relatively fixed for a period of time, derived from generalisations from investigation with a 'sample' of professionals. Such accounts are commonly derived from a consensus among groups identified by professional bodies and organisations and may be refreshed occasionally as major changes in the profession occur or when regulators require (for example every three to five years). They provide a normative snapshot of what is thought to be required of members at the point at which the statements were constructed. Moreover, as Fenwick suggests, they often produce what they seek to measure (Fenwick 2009). As a durable framework, their capacity for change is limited. They are necessarily linked to practices current at the time of their development as filtered through a limited number of informants and generalised across multiple settings. Such frameworks are particularly bounded by what may have been appropriate when they were developed, although attempts are sometimes made to include 
This is the final version submitted to Studies in Continuing Education and published in 2015. Please do not cite this version. To view the published article use the following: DOI: 10.1080/0158037X.2015.1022717

predictions of what might be needed for changing practice. There is, at least in part, a relatively static representation of the profession.

In contrast, we understand a second perspective as idiographic. The idiographic focuses on the unique and contingent opportunities available to practitioners. Idios, in ancient Greek, refers to private or personal and this is manifest in the particularities of accounts of professional learning derived through empirical research. Much of the research from the field of workplace learning or work and learning (e.g. Malloch et al. 2011) can be viewed as idiographic. From this perspective, knowledge of professional learning is gained from empirical investigations of professionals' work. These may be from ethnographic studies, interviews, analyses of practices, and so on. They may also arise from explorations of professionals themselves in their own context. These provide information about what and how professionals learn through the everyday means by which professionals conduct their jobs and extend themselves to face new problems and challenges. Such a perspective emphasises context-specific features, collective activities and the complexity of practice. However, both views draw on relatively restricted examples of the phenomena being observed. Competences or capabilities are drawn from selected groups of expert informants and while they may be given wider exposure among other members of the profession, the decisions made are typically from a limited group who act as de facto guardians of the profession. Research studies are restrictive in different ways. It is rare to find empirical investigations across cohorts of a profession, for example. Often rich detailed data is generated from which it may not be possible to generalise to a particular population.

Frameworks for continuing learning used by employing organisations or educational institutions can be seen as nomothetic or ideographic. For example, for employing organisations, CPE or more commonly named continuing professional learning (CPL), manifests in a range of technologies to capture, measure and reward the professional learning of its employees. Like professional bodies these typically appear as nomothetic statements, standards or capability frameworks that seek to capture and measure professional learning. Most of these frameworks privilege formal knowledge despite the decades of research that indicate that 'most working practices cannot be adequately described by codified knowledge alone, and selfaccounts of learning usually focus on formally recognised outcomes that can 
This is the final version submitted to Studies in Continuing Education and published in 2015. Please do not cite this version. To view the published article use the following: DOI: 10.1080/0158037X.2015.1022717

easily be described and justified' (Eraut 2012, p.22). Educational institutions' practices can also be described as nomothetic. Their professional education entry programs include a focus on developing expertise which will equip newcomers to the profession, and to recognise and seek out professional learning opportunities throughout their careers. External accrediting bodies look to university courses to prepare students to meet the nomothetic professional requirements laid down by an appropriate authority.

\section{Differing purposes of CPE.}

A third way of understanding the dissonance between CPE frameworks and research on workplace learning is through examining the purposes of common CPE frameworks, both for professional bodies and employing organisations.

Professional bodies can be seen here to have a clear commitment to enhance and ensure the expertise of their members. They do this through the provision of standards that those entering the profession must meet and, commonly, through the requirements that professionals must address to maintain professional standing. This is seen clearly in an Australian engineering professional body's statement:

The intellectual capital of the engineering profession grows as its members invest in continuing professional development (CPD). An individual's potential for lifetime employability depends on the high levels of professional competence that come from continually upgrading skills and knowledge. Businesses gain a competitive edge when principals and staff identify learning needs and set about achieving them systematically. In today's rapidly changing technological world it is no longer possible to rely on basic engineering studies alone to provide professional advice and services competently. (http://www.engineersaustralia.org.au/nerb/cpd-andaudits).

Some form of continuing professional education is typically part of the requirements for professional status. While professional bodies are continually extending the repertoire of approaches they use for CPE purposes (through, for example, accreditation of specialisms, case studies with reflective commentaries, learning logs etc.) the most common forms of CPE involve participation in recognised events and activities for which sign-off on participation is required. In some cases there is little focus by the professional 
This is the final version submitted to Studies in Continuing Education and published in 2015. Please do not cite this version. To view the published article use the following: DOI: 10.1080/0158037X.2015.1022717

association on what is learnt: 'being there' or 'saying what you do' constitutes learning.

When professional bodies recognise the limitations of such an approach and extend the repertoire of activities that they recognise, they face the challenge of generating additional work both for members and for the association in documenting compliance. In alternative approaches, such as reflective journals/ logs, self-assessment, they also face the difficulty of making clear judgements about whether requirements have been met. The professional associations face a tension between having activities for which it is easy to judge compliance but which do not necessarily lead to relevant learning, e.g. attendance at events, and rich learning activities which may be worthwhile to those who engage in them, but have considerable compliance costs for all parties. A further tension arises when it is the professional body itself that offers the CPE events and activities. Some bodies have become dependent on business models that generate considerable income from CPE activities to fund the organisation.

Similarly, companies and other employing organisations have a substantial interest in ensuring that their employees continue to learn. They need to do so in order to be prepared for the challenges and changes faced by the organisation. Many have developed their own learning and development frameworks, typically attached to performance management systems, sometimes called corporate capability frameworks. For example, one organisation in which we conducted research had well codified sets of corporate capabilities which did not map onto those of the professional body but represented the capabilities needed for the particular kind of work of that organisation. Taken in isolation such statements are not characteristically different from statements of capabilities created by accreditation bodies or post secondary institutions. They are however, taken to be uniquely suited to the particular organisation that generates them.

The differing purposes for which CPE are used - by professional organisations and employing organisations_-privileges different types of assumptions about learning and practice. For example, those professional bodies adopting a business model which requires thousands of students to attend courses and examinations privilege formal codified knowledge and formal assessment and learning processes. Many organisations, although 
This is the final version submitted to Studies in Continuing Education and published in 2015. Please do not cite this version. To view the published article use the following: DOI: 10.1080/0158037X.2015.1022717

supporting learning at work, often require codified capability statements to easily assess performance. They thus send a mixed message to their employees.

\section{Learning elicited from practice - an example from our research}

We have seen examples of the differing conceptions of professional learning and practice in CPE frameworks and workplace learning research in our own work with both engineers and health professionals. By way of illustration we draw on one such study: with engineers. Our study focused on the learning of engineers within a particular Australian company involved in large-scale construction projects. The organisation involved placed great importance on the development of the professionals in their employ. They "pride [themselves] on being a market leader in targeting training, career development and remuneration [and] provide long-term career options" within the organisation. A comprehensive and considered framework set out the organisation's expectation in terms of key accountabilities, various technical and behavioural capabilities along with the qualifications and development of the engineers they employ. ${ }^{1}$ This framework was developed in conjunction with input from a team of over 40 experts within the organisation - as such, it too can be considered as having been developed from a nomothetic perspective and based on an individualised conception of learning. It is important to also point out that the framework is considered the main professional requirement of the engineers employed in the organisation: with the exception of some states of Australia where the membership of engineers is legislated, the organisation did not require its employees to be members of the national professional body.

In contrast to these capability statements, our own research focussed on how engineers learn through their everyday work when not immediately required through professional accreditation or performance management. While the capability statement was considered as background to our investigation, it was the practice of the professionals themselves that attracted our attention.

\footnotetext{
${ }^{1}$ Although the organisation shared this newly developed organisational document with the researchers, it was under the proviso that they did not publish or make public any specificities of the document.
} 
This is the final version submitted to Studies in Continuing Education and published in 2015. Please do not cite this version. To view the published article use the following: DOI: 10.1080/0158037X.2015.1022717

Our current research studies have been framed by the use of practice theory perspectives taken up in professional learning research, as described above (see Hager, Lee, and Reich 2012b for examples). Practice theorists such Schatzki (2012) urge an emphasis on practices. Our focus was on the practice as the primary unit of analysis, that is, the complex interactions of sayings and doings, and the relationship with other persons and material objects. Practices do not come about completely anew each time work needs to be conducted, but have a practice history that preconfigures the character of the particular practice concerned. Practices are not individual activities. They are complex embedded contextual interactions and have a purposeful outcome.

The practice lens provides a new and different way to understand the learning of professionals, such as engineers - one that shifts from a normalising focus such as attendance at seminars, workshops and the like to everyday work activities. This practice lens leads us to notice how professional practice (engineering in this case) consists of 'bundles' of interrelated practices and material arrangements. Each practice consists of activities, material 'things' and bodies. It is purpose-focused and there is a shared understanding within the profession about the practice. These practices are prefigured and each instantiation keeps alive the possibility for reconfigurement (i.e., change).

For example, in our study of engineers, our task was to elicit the practices undertaken by groups of civil engineers engaged in construction work. We interviewed engineers in groups and individually and took part in visits to their workplaces. We were concerned to find out what they did in their normal work. While not exhaustive, among the practices we (and they) identified (and they labelled) were site walks and monthly planning reviews (Rooney et al 2014; Reich et al 2014; Rooney et al 2014).

What then were the features of these practices? Taking site walks, it was a practice undertaken every morning to examine any changes from the previous day to the site such as erosion, vandalism, rainwater damage. The practice was a 'knowing-in-practice' (Gherardi 2012) as "despite extensive design and planning, 'knowing' the practice is enacted in the site. As one engineer said, 
This is the final version submitted to Studies in Continuing Education and published in 2015. Please do not cite this version. To view the published article use the following: DOI: 10.1080/0158037X.2015.1022717

... most engineering jobs you can't price, unless you've seen the site. ... The plans only tell half the story to what's actually out here. Because the plans tell you what its going to look like when its finished. They don't tell you what it looks like when it starts (Tim - estimator)" (Reich et al 2014: 8)

It was a collective knowing-in-practice which was embodied and relational with a wide range of human actors including clients, sub-contractors, designers, site managers, environmental scientists, etc. Non-human actors, included Blackberries and computers, diaries, plans as well as less tangible actors such as the plans, codes of conduct and multiple regulations of Federal, state and local authorities and international standards, all shaped the enactment of the particular site walk. The site walk was emergent -required changes to the practices could not be predicted in advance. And it was an important site of learning as the engineers engaged in relational practices with many other professions and occupations. Through a practice perspective, the site walk could be seen as not static, easily specifiable or normatively prescribed (like competency or capability frameworks) but 'messy', unpredictable, complex and highly contextualised. (Rooney et al 2014; Reich et al 2014; Rooney et al 2014 for more details on this research).

\section{Discussion - alternatives for continuing professional learning}

As our research on professional engineers indicates, professionals engage in sets of complex, unpredictable and emergent practices. As part of these practices, engineers learn to work and solve the problems implicated in doing work. They typically don't talk about what they are doing in this regard as learning - they see it as 'doing their job'—but they readily accept such a description when it is put to them. We suspect they resist describing it as a learning activity because learning is not their prime reason for doing it (Boud and Solomon 2003).

This account has important implications for anyone wishing to construct a program of learning around the notion of professional practice. A program of learning is manufactured in situ from a program of work: if appropriate work is selected that gives rise to the learning desired, then that constitutes a program of learning. It is a de facto curriculum that comes with its own in-built pedagogy, the pedagogy of usual work relationships and activities. If the range of learning needs to be extended, then it can be done through an extension of work or types of work. Different work allocations, different 
This is the final version submitted to Studies in Continuing Education and published in 2015. Please do not cite this version. To view the published article use the following: DOI: 10.1080/0158037X.2015.1022717

colleagues and other participants create different learning. Such an arrangement is of course not novel. It bears a close resemblance to the notion of work rotations, which are commonplace in medical education and a number of other professions. Doctors learn, for example, through placements in a wide variety of different kinds of hospital departments where they confront and learn in ways necessary to deal with the variety of conditions they face. What is different here is seeing varied work as an explicit continuing professional learning strategy beyond the early days of professional induction and having different stakeholders able to deploy the strategy consciously.

To sum up, there are tensions between the statements inscribed by professional bodies and organisations and the accounts of professional practices elicited from work itself. The former prescribe what should be learned, or more particularly the competencies that should be demonstrated. The latter provides an account of the practices and the learning entwined in it. Of course, these accounts address quite different purposes. Capability or competency frameworks seek to map the entire body of outcomes for someone to be regarded as a capable professional or as someone to be recognised and rewarded within a company. But what is represented in these frameworks are an extension or generalisation from remembered work by those whose views comprise the framework. It remains static and codified, and focused on an individual's knowledge and performance, downplaying the relational, collective and emergent nature of practice.

The mapping of learning from professional practice itself has a different intention, and its own limitations. It looks to understand the nature of practice and how learning is situated within it. It is necessarily contextualised, embodied and relational, which means that generalisation must be undertaken with great caution. While strong on the particular, it does not in itself seek to generalise. To do so would take analysis beyond the assumptions of practice theory. For instance, it might be possible to consider the set of professional practices undertaken by construction engineers on major projects, but dangerous to assume findings could be transferred to small scale projects, or to those not involved in civil construction or undertaken in quite different cultural contexts.

But professional practice needs to move beyond this binary - practice and practising a profession is a complex, messy pursuit which cannot be neatly 
codified. However, drawing on a practice perspective, we suggest, could be a productive way of finding more effective ways of considering continuing professional education. It involves recognising that learning is emergent, and that it is a response to circumstances that cannot be predetermined.

Specifying in advance what it should be brings benefits of standardisation but risks distracting attention from what is most needed to practice now and being seen as irrelevant by employers. The challenge is to work out ways of capturing and representing learning in more dynamic ways as described above and to develop CPE/CPL frameworks which acknowledge this complexity and messiness of professional practice; the collective nature of learning and practice and the dynamic and ever-changing organisational work environment - as well as appreciating the professional association and employing organisation's position. It also requires acknowledgement that it is too risky to establish authoritative sets of standards and competencies that represent the profession or organisation. These are normalising devices that typically omit the core requirement of professional work: to be able to respond to challenges not envisaged in the canonical statements. A more modest approach in framing such statements is needed. This includes a recognition that it is the capacity to learn from experience and adapt to change that characterises contemporary professional work.

\section{Conclusion}

The question we posed at the start of this paper was about continuing professional education frameworks and practices not reflecting contemporary workplace learning research. CPE has been framed around the common practice of establishing competency or capability frameworks and using these to drive educational provision. We have seen that such frameworks aim to capture what are the common and pervasive competencies that have been required. They largely exist independent of the contexts in which practitioners operate and this means that some of them struggle to find ways of addressing the requirements of actual work. These frameworks resist particular professional practice because they exist to transcend it. However, by doing so they become disengaged and less relevant to working professionals. A greater emphasis on research about what professionals do, and on planned processes of review and change can help these frameworks become more relevant. 
This is the final version submitted to Studies in Continuing Education and published in 2015. Please do not cite this version. To view the published article use the following: DOI: 10.1080/0158037X.2015.1022717

What we know about learning and practice is building rapidly, but we can say that learning is prompted by engaging in work with others that extends the range of practice of participants. Perhaps, we will see expectations of professionals evolve from requirements to demonstrate particular competencies, to those which require engagement in an extended range of practices and the conditions in which they occur. Yet we also appreciate the imperatives of organisations that employ professionals and those who monitor and provide for the professional learning of professionals. The future challenges will be to develop the frameworks and structures to support professional learning which is collective, dynamic and embedded in everyday practices yet speak to the very real concerns of professionals, organisations and professional bodies.

\section{References}

Boud, D., and P. Hager. 2012. "Reconceptualising Continuing Professional Development through Changing Metaphors and Locations in Professional Practices." Studies in Continuing Education 34 (1): 17-30.

Boud, D. and Solomon, N. 2003. "I don't think I am a learner': Acts of Naming Learners at Work", Journal of Workplace Learning, 15 (7-8): 326-331.

Eraut, M. 2012. "Developing a Broader Approach to Professional Learning." In Learning Trajectories, Innovation and Identity for Professional Development, edited by A. McKee and M. Eraut, Innovation and Change in Professional Education 7. 21-45. Dordrecht: Springer Science + Business Media.

Fenwick, T. 2009. "Making to measure? Reconsidering Assessment in Professional Continuing Education." Studies in Continuing Education 31 (3): 229-244.

Fenwick, T., R. Edwards, and P. Sawchuck. 2011. Emerging Approaches to Educational Research: Tracing the Socio-material. London: Routledge.

Fenwick, T., M. Nerland, and K. Jensen. 2012. "Sociomaterial Approaches to Conceptualising Professional Learning and Practice." Journal of Education and Work 25 (1): 1-13.

Fenwick, T and M. Nerland (Eds). 2014. Reconceptualising Professional learning: Socio-material Knoweldge,Practices and Responsibilities. London: Routledge.

Gherardi, S. 2000. "Practice-based Theorizing on Learning and Knowing in Organizations." Organization 7 (2): 211-223. 
This is the final version submitted to Studies in Continuing Education and published in 2015. Please do not cite this version. To view the published article use the following: DOI: 10.1080/0158037X.2015.1022717

Gherardi, S. 2012. How to Conduct a Practice-based Study: Problems and Method. Cheltenham: Edward Elgar.

Hager, P. 2011. "Theories of Workplace Learning." In The SAGE Handbook of Workplace Learning, edited by M. Malloch, L. Cairns, K. Evans, and B. O'Connor, 17-31. London: SAGE Publications.

Hager, P. and P. Hodkinson. 2009. "Moving Beyond the Metaphor of Transfer of Learning." British Educational Research Journal 35 (4): 619-38.

Hager, P. and M. Johnsson 2012, "Collective Learning Practice". In Practice, Learning and Change: Practice-theory Perspectives on Professional Learning , edited by ", in P. Hager, A. Lee and A. Reich, 249-65. Dordrecht: Springer.

Hager, P., A. Lee, and A. Reich, eds. 2012a. Practice, Learning and Change:

Practice-theory Perspectives on Professional Learning. Dordrecht: Springer.

Hager, P., A. Lee, and A. Reich. 2012b. "Problematising Practice, Reconceptualising Learning and Imagining Change." In Practice, Learning and Change: Practice-theory Perspectives on Professional Learning, edited by P. Hager, A. Lee, and A. Reich, 1-16. Dordrecht: Springer.

Johnsson, M., and D. Boud. 2010. "Towards an Emergent View of Learning Work." International Journal of Lifelong Education, 29 (3): 355-368.

Mos, L.P. 1998. "On Methodological Distinctions: Nomothetic Psychology, or Historical Understanding." Theory \& Psychology, 8 (1): 39-57.

Malloch. M., L. Cairns, K. Evans, and B. N. O'Connor, eds. 2011. The SAGE Handbook of Workplace Learning. London: SAGE Publications.

Nerland, M., and K. Jensen. 2012. "Epistemic Practices and Object Relations in Professional Work." Journal of Education and Work 25 (1): 101-120.

Nowotony, H., P. Scott, and M. Gibbons. 2003. "'Mode 2' Revisited: The New Production of Knowledge." Minerva 41: 179-194.

Reich, A and P. Hager. 2014. "Problematising practice learning and change: Practice-theory Perspectives on Professional Learning. In Journal of Workplace Learning. 26 (6/7): 418-438.

Reich, A., D. Rooney, A. Gardner, K. Willey, D. Boud, and T. Fitzgerald, 2014. "Engineers' Professional learning : A Practice-theory Perspective," European Journal of Engineering Education.

Rooney, D., A. Gardner, K. Willey, A. Reich, D. Boud and T. Fitzgerald. In press, "Reimagining Site-walks: Sites for Rich Learning." In Australasian Journal of Engineering Education.

Rooney, D., K. Willey, A. Gardner, D. Boud, A. Reich \& T Fitzgerald. 2014, "Engineers' Professional Learning: Through the Lens of Practice" edited by B. Williams, J. Figueiredo \& J. Trevelyan, 265-83. Engineering 
This is the final version submitted to Studies in Continuing Education and published in 2015. Please do not cite this version. To view the published article use the following: DOI: 10.1080/0158037X.2015.1022717

Practice in a Global Context: Understanding the Technical and the Social, Leiden, The Netherlands: CRC Press.

Schatzki, T., C. Knorr Cetina, and E. von Savigny (eds) 2001a.The PracticeTurn in Contemporary Theory, New York: Routledge.

Schatzki,T . 2012a. , 'Foreword', in Hager, P., A. Lee. and A. Reich. (Eds), Practic, learning and Change: Practice-theory Perspectives on Professional Learning. 13-26Dordrecht: Springer.

Schatzki, T. 2012b. "A Primer on Practices: Theory and Research." In Practice-Based Education: Perspectives and Strategies, edited by $\mathrm{J}$. Higgs, R. Barnett, S. Billett, M. Hutchings, and F. Trede. Sense Publishers: Rotterdam.

Unwin, L., and A. Fuller. 2003. Expanding Learning in the Workplace: Making More of Individual and Organisational Potential. National Institute of Adult Continuing Education: Leicester, UK. 